\section{MS37 P01}

Wave field Enhancement during Grazing Incidence Xray Backscattering Diffraction Hakob (Akop) P. Bezirganyan $^{\mathrm{a}}$, Siranush E. Bezirganyan, ${ }^{\mathrm{b}}$ Petros $\mathrm{H}$. Bezirganyan (Jr.), ${ }^{\mathrm{c}}$ Hayk H. Bezirganyan (Jr.), ${ }^{a}$ Department of Solid State Physics, Faculty of Physics, Yerevan State University, Yerevan, Armenia. ${ }^{\mathrm{b}}$ Department of Medical \& Biological Physics, Yerevan State Medical University after Mkhitar Heratsi, Yerevan, Armenia. ${ }^{\mathrm{c}}$ Department of Computer Science, State Engineering University of Armenia, Yerevan, Armenia. ${ }^{\mathrm{d}}$ Faculty of Computer Science and Applied Mathematics, Yerevan State University, Yerevan, Armenia.

E-mail: hbezirganyan@x-rom.org

Keywords: $\mathrm{Si} / \mathrm{SiGeC} / \mathrm{Si}$, grazing incidence X-ray diffraction, X-ray back reflection

The growth of $S i_{1-\alpha-\beta} G e_{\alpha} C_{\beta} / S i$ carbon containing films is not an easy task because of the high-mismatch between the silicon and carbon lattices, the low solubility of carbon in silicon and germanium, and the tendency of carbon to precipitate into $\beta$-polytype silicon carbide [1]. The same difficulties are arising during the epitaxial growth of silicon cap layer on the $S i_{1-\alpha-\beta} G_{\alpha} C_{\beta}$ layer because the substitutional carbon concentration between these two layers is depleted.

In purpose to avoid such difficulties, a model of a straincompensated $S i / S i_{-\alpha-\beta} G \theta_{\alpha} C_{p} / S i$ heterostructure is proposed in the presented theoretical paper. X-ray diffracting lattice planes of silicon cap layer and straincompensated $S i_{1-\alpha-\beta} G \theta_{\alpha} G_{g}$ layer, which is epitaxially grown on the bulk relaxed silicon substrate, have the same value of the spacing period $d_{R \text { hil }}$ along the growth surface. However, there exists a longitudinal shift between their spacing periods caused by the misfit dislocations. This paper concerns the non-destructive investigations of bicrystal-like model of heterostructure by the extremely sensitive grazing-angle incidence $\mathrm{x}$-ray backscattering diffraction (GIXB) technique $[2,3]$. The development of such non-destructive investigation method is in the focus of fundamental aspects of material research, crystal engineering etc.

We consider theoretically in presented paper an enhancement phenomena of the x-rays reflected from the mentioned heterojunction depending on the shift between the cap layer and substrate spacing periods. As an illustrative example we consider a GIXB by the (444) diffracting lattice planes of the heterostructure, which are normal to $\mathrm{x}$-ray entrance surface. It is shown that the increase in the value of the space phase along the heterojunction's interface between silicon cap layer and strain-compensated $S i_{1-\alpha-\beta} G \varepsilon_{\alpha} C_{\beta}$ layer leads to essential enhancement of the reflectivity coefficient.

[1] Loup V., Buiu O., Hartmann J. M., Rolland G., Holliger P., Laugier F., Lafond D., Semeria M. N., Besson P., Gentile P., Semicond. Sci. Technol., 2003, 18, 352.

[2] Bezirganyan H.P., Bezirganyan P.H., Phys. Stat. Sol. (a), 1988, 105,345 .

[3] Bezirganyan H.P., Phys. Stat. Sol. (a), 1988, 109, 101.

\section{MS37 P02}

Optimal Thickness of Non-diffracting Subsurface Mirrors of X-Ray Optical Memory Siranush E. Bezirganyan $^{\mathrm{a}}$, Hakob (Akop) P. Bezirganyan, ${ }^{\frac{\mathrm{b}}{\text { P }} \text { Petros H. }}$
Bezirganyan (Jr.), ${ }^{\mathrm{c}}$ Hayk H. Bezirganyan (Jr.), ${ }^{\mathrm{d}}$ ${ }^{a}$ Department of Medical \& Biological Physics, Yerevan State Medical University after Mkhitar Heratsi, Yerevan, Armenia. ${ }^{\mathrm{b}}$ Department of Solid State Physics, Faculty of Physics, Yerevan State University, Yerevan, Armenia. ${ }^{\mathrm{c}}$ Department of Computer Science, State Engineering University of Armenia, Yerevan, Armenia. ${ }^{\mathrm{d}}$ Faculty of Computer Science and Applied Mathematics, Yerevan State University, Yerevan, Armenia.

E-mail: sira be@yahoo.com

Keywords: $x$-ray optical memory, grazing incidence $X$ ray diffraction, $X$-ray back reflection

$\mathrm{X}$-ray optical memory $(X-R O M)$ is a semiconductor wafer, in which the high-reflectivity $\mathrm{x}$-ray mirrors are embedded. Data are encoded due to certain positions of these mirrors. The X-ray-based optical data storage devices e.g. could operate using the grazing-angle incidence $\mathrm{X}$-ray backscattering diffraction $(G I X B)$ technique [1-3]. Grazingangle incident $\mathrm{x}$-ray configuration allows the handling of data from very large surface area and, consequently, the data read-out speed is much faster than in optical data readout systems (Fig.1):

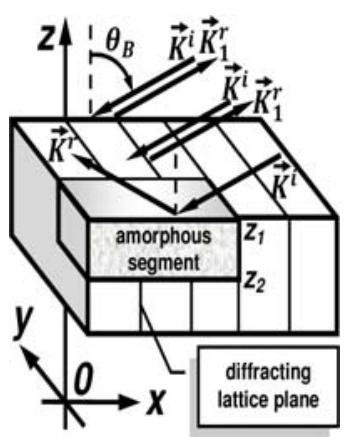

Fig.1. The $G I X B$ by twosegment element of x-ray optical memory in the case of specular vacuum wave suppression mode. $\theta_{B}$ is kinematic Bragg angle, $T=\left(z_{1}-z_{2}\right)$ is the thickness of amorphous component generated in crystalline substrate.

According [3], the most part of x-ray wave field energy is back warded from the X-ROM's crystalline substrate caused by the X-ray specular (mirror) wave suppression phenomenon. Consequently, if the GIXB takes place in conditions of the specular vacuum wave suppression mode, then the reflected wave $\boldsymbol{K}^{\boldsymbol{r}}$ (contrary to other existing x-ray diffraction methods) practically carries the information only about non-diffracting subsurface mirrors [4].

We consider in presented theoretical paper the effective depths of penetration of the non-homogeneous $\mathrm{x}$-ray wave fields in crystalline substrate and amorphous segments of the X-ROM respectively, when the angle of incidence $\theta^{i}$ of the X-ray micro beam $\boldsymbol{K}^{\boldsymbol{i}}$ is exactly satisfying the Bragg's Law, i.e. $\theta^{i}=\theta_{B}$, where $\theta_{B}$ is the Bragg angle. As a result, the condition is obtained for optimal thickness $T=\left(z_{1}-z_{2}\right)$ of the $X$-ROM amorphous reflecting domains (speckles).

[1] Bezirganyan H.P., Bezirganyan P.H., Phys. Stat. Sol. (a), 1988, 105,345 .

[2] Bezirganyan H.P., Phys. Stat. Sol. (a), 1988, 109, 101.

[3] Bezirganyan H.P., Bezirganyan H.H. (Jr.), Bezirganyan S.E., Bezirganyan P.H. (Jr.), Opt. Comm., 2004, 238/(1-3), 13.

[4] Bezirganyan H.P., Bezirganyan H.H. (Jr.), Bezirganyan S.E., Bezirganyan P.H. (Jr.), Acta Cryst. A, 2005, 61, C448. 